Male circumcision

\title{
Male circumcision: a scientific perspective
}

\section{R V Short}

\section{The health benefits of male circumcision are wide ranging}

n this issue, John Hutson has reiterated the conventional Western 1 medical view that "the surgical argument for circumcision of all neonatal males at present is very weak" and he criticises many of the circumcisions performed in later childhood, without anaesthesia, as "physically cruel and potentially dangerous" [see page 238]. ${ }^{1} \mathrm{He}$ is also of the opinion that "the diseases which circumcision is able to prevent are uncommon or even rare". But therein he errs, and greatly errs.

He cites only two publications dealing with the protective effect of male circumcision against HIV infection, and makes no mention of the important recent metaanalysis of Weiss, Quigley, and Hayes ${ }^{2}$ which shows conclusively from a large number of studies that male circumcision at least halves the relative risk of HIV infection throughout sub-Saharan Africa. ${ }^{3}$

Would that we could share Hutson's optimism that "we are not certain at present whether AIDS is going to be an even more widespread disease in the future or whether it will be abolished by some new treatment". At the 14th International AIDS Conference in Barcelona in July 2002 we were informed that currently 40 million people are infected with HIV, with five million new infections a year; the AIDS pandemic is only just beginning. There is no cure in sight, and vaccines still remain a distant hope. ${ }^{4}$ Faced with such dismal future prospects, is it ethical to dismiss a simple prophylactic surgical procedure that can halve male rates of infection?

The case for male circumcision has been further strengthened by a recent multinational case controlled study in developed and developing countries in Europe, Asia, and South America, which has shown that circumcised men are two thirds less likely to have human papilloma virus infection of the penis, and their female partners less than half as likely to develop cervical cancer, when compared with uncircumcised men and their partners. ${ }^{5}$ As cervical cancer is the second commonest cancer of women worldwide, these results should surely make the most reluctant surgeons think again.

But nevertheless, Hutson does have a point. Male circumcision is not without its risks. When is it best to perform the operation? Perhaps late in childhood, when the foreskin has separated from the glans penis, and the boy can give informed consent to the procedure. Such timing would also ensure a more immediate impact on the transmission of HIV. How should the operation be performed? The American PlastiBell device has one of the lowest complication rates, providing a "no scalpel" circumcision by means of a ligature tied around the base of the foreskin when it is stretched over a protective plastic cap which covers the glans penis. This

\section{Value judgment, harm, and religious liberty}

\section{A $M$ Viens}

Parents' freedom to choose infant male circumcision is the correct policy

ndividuals and groups lobbying to have infant male circumcision prohibited or restricted often argue that the practice of routinely circumcising infants is unjustified. For instance, in this issue of the journal, John Hutson device is now off patent, and could be mass produced at very low cost.

Even if the rest of the world continues to reject male circumcision, there are a billion Muslims for whom it will remain a fact of life. Islamic nations such as Egypt, Sudan, Iraq, Iran, Pakistan, Bangladesh, and Indonesia have spectacularly low rates of HIV infection compared with their neighbours, due at least in part to male circumcision. Now would be an opportune time for the Western world to profit from this Islamic experience, while offering to help them improve their surgical procedures.

If we believe in evidence based medicine, then there can be no debate about male circumcision; it has become a desirable option for the whole world. Paradoxically, this simple procedure is a life saver; it can also bring about major improvements to both male and female reproductive health. Rather than condemning it, we in the developed world have a duty to develop better procedures that are neither physically cruel nor potentially dangerous, so that male circumcision can take its rightful place as the kindest cut of all.

J Med Ethics 2004;30:241.

doi: 10.1136/jme.2002.002576

Correspondence to: Professor R V Short Department of Obstetrics and Gynaecology, Royal Women's Hospital, 132 Grattan Street, Carlton, Victoria 3053, Australia; r.short@ unimelb.edu.au

\section{REFERENCES}

1 Hutson JM. Circumcision: a surgeon's perspective. J Med Ethics 2004;30:238-40.

2 Weiss HA, Quigley MA, Hayes RJ. Male circumcision and risk of HIV infection in subSaharan Africa: a systematic review and metaanalysis. AIDS 2002;14:2361-70.

3 Reynolds SJ, Shepherd ME, Risbud AR, et al. Male circumcision and risk of HIV-1 and other sexually transmitted infection in India. Lancet 2004:363:1039-40.

4 UNAIDS. Report on the global HIV/AIDS epidemic. Geneva: UNAIDS, 2002:226. 5 Castellsagué X, Bosch FX, Munoz N, et al. Male circumcision, penile human papillomavirus infection, and cervical cancer in female partners. New Eng J Med 2002;346:1105-12.

argues that it is virtually impossible to justify a policy in which the medical establishment should be able to embark on a "mass circumcision" campaign of $100 \%$ of the infant male population (with the exception, of course, where it would be contraindicated by the presence of an anatomical or physiological abnormality) [see page 238]. ${ }^{1}$

Indeed, I would be hard pressed to find anyone who could rationally disagree with this contention. However, this is because no one is currently arguing for the enactment of a policy that stipulates that all healthy male infants should be routinely circumcised (independent of parental choice). Arguments seeking to support a prohibition of 
"routine infant circumcision", such as the one by Hutson, are arguing against a straw man-and a pitiful one at that. ${ }^{2}$ Such arguments only serve to misconstrue the debate and avoid engaging in the real and pressing issues concerning the legitimacy of the provision of this procedure.

The questions that should be considered, and the ones which I shall be interested in discussing here, are what reasons are justifiable for allowing parents to choose to have their son circumcised? After well informed and careful deliberation should parents have the freedom to choose to have their son circumcised? These are the most relevant questions to be considered because there is a growing collection of citizens, medical practitioners, and lawyers who are currently lobbying for the practice of infant male circumcision to be outlawed-for example, there is a bioethicist who argues that the criminal law should be used to prohibit the procedure as an instance of aggravated assault. ${ }^{3}$

For a number of people, if successful, such an action would have the notable impact of interfering with their ability (as parents or guardians) to determine what is in the best interest of their child and/or the freedom to raise their children under the tenets of a particular religious doctrine or community. Although customarily parents are seen as the best arbiters of decisions affecting their child's wellbeing-not because parents make the best decisions for their children, but because parents ought to be accorded the freedom and autonomy to make such choices-conceivably it could be the state or medical establishment who will possess the power to decide whether parents should be allowed to make such decisions (at least, with respect to this issue).

This is an important political consideration, but it also has a special salience for bioethics as well. It illustrates the potential extent to which societal and medical institutions can enact rules and policies that can constrain or restrict a person's ability to act in certain ways. Thus, of particular importance will be how, and to what extent, are these institutional norms in medicine (that have so much power over our lives) justified-especially in the face of reasonable disagreement in society about what is valuable, good, right, and so on. We will want to ensure that the justification proffered for limiting individual freedom and choice is exceedingly robust and fair.

I shall argue that in order for policy concerning the prohibition of circumcision to be acceptable it would have to be demonstrated that such a policy could be justified to those individuals with reasonable yet conflicting doctrines and whom this policy would concern. As there are reasonable doctrines held by individuals that contain deeply held social, cultural, and religious views concerning the value of having their son undergo circumcision, current attempts to advance a policy which prohibits the provision of this procedure that fail to take these value judgments seriously would be unjustified. I argue that the proper assessment of the moral permissibility of circumcision needs to be made by parents on the basis of an informed deliberation concerning all the potential medical and non-medical benefits and risks of the procedure.

\section{I}

Generally, it is very difficult for individuals to view their own conception of the good as anything but true. After deliberating and fixing a particular set of moral beliefs, it is difficult for an individual to view other divergent moral beliefs as anything but false. For if an individual did not think their considered moral judgements about how to live their life were true or best, there would be little reason to hold those beliefs, let alone act on them. The existence and extent of moral diversity in society present a number of practical problems, such as disagreements and even incompatible views about what is valuable. With so many clearly opposing, and at times contradictory, conceptions of the good within society, there are instances when it is difficult to reach a meaningful consensus on important moral issues (especially on highly emotive issues). The best we can hope for is to structure our institutions and practices (and the norms that govern them) in a way that attempts to take seriously the fact that reasonable people will disagree about what is valuable, good, and right, and how given this fact we can arrive at fair and justifiable ways to regulate our lives in society. ${ }^{4}$

In order for biomedical public policy to be seen as fair and sustainable, what is needed is an understanding of the proper type of justification required when we collaborate on reasonable terms with members of society who hold different moral commitments. What needs to be recognised is that the operation of an agent's moral conception of the good in their personal day to day ethical deliberations should be markedly different from the use of public reason to arrive at public policy in which all citizens with reasonable conceptions of the good could uphold as fair and justifiable. The reasoning and justification involved with questions of the public on the one hand, and that of the personal concerning how one should live one's life on the other hand, are in a different justificatory class. Our process of justifying public policy must bracket off reference to substantive conceptions of the good in order to ensure that particular beliefs and values are not forced onto others.

In the case of specific policy questions, such as whether it is justified to allow parents to choose whether or not they can circumcise their son, we are not seeking to advance a policy that all members of society will necessarily come to endorse, but to aim to advance a policy that no one could reasonably reject. Such a conception recognises that there is a disjunction of reasonable conceptions of the good to be found within society, and views as its task, according to Donald Ainslie, "not [as] the [resolution of] disagreements, but to see what policy can be justified to people despite their disagreements". ${ }^{5}$ The important point here is that when bioethicists are concerned with the construction of biomedical policy, in order to advance policy that will be seen as fair and justifiable to reasonable people, it cannot be done at the level of conceptions of the good. When formulating the norms governing biomedical policy, bioethicists must take as their starting point the fact that a plurality of reasonable conceptions of the good in society will arrive at different conclusions about what is valuable or what promotes wellbeing. Moreover, as value judgments differ among reasonable individuals, what one individual views as harmful may not be perceived as such by others. In the following sections, it will be argued that no persuasive case has been made in favour of limiting the liberty of parents concerning their ability to choose whether it is in their son's interest to be circumcised.

\section{II \\ (A) Religious liberty and the freedom to choose}

Traditional justifications for the permissibility of religious infant male circumcision have been predicated on arguments for religious liberty. ${ }^{6}$ The law generally provides parents with the freedom and discretionary authority, in the course of raising their children, to decide what is in the interest of their children (within reason, of course). In the case of religious circumcision, a parent's decision to have their son circumcised is justified on the basis of their religious views (for example, the practice is justified by appealing to a canonical text). Although some parents may choose not to have their son circumcised or other parents may choose to have their son circumcised for non-religious reasons, what is seen as important (in terms of justification of 
the decision) is that it will be agent relative-that is, justifiable reasons to circumcise or not circumcise their son will be based on the parents' conception of the good, and not that of the physician, bioethicist, or neighbour. Although these agent relative reasons may be permissible or non-permissible, in order for them to be considered justified reasons for or against the procedure, they need to have their basis in the parents' values.

What anticircumcision proponents maintain is that parents are unjustified in believing their child would also maintain their religious values. It is argued that because we do not know if a child will decide to become a follower of their parents' religion, it would be better if circumcision decisions were delayed until adulthood, so that if an individual wants to remain a member of the religious community and his uncircumcised status was a barrier to religious marriage or burial, he could consent to the procedure as an adult. The problem is that such decisions are not seen to be able to be delayed until this time-the religious significance of the procedure is to be done in childhood. An individual's understanding of a good life (which will include raising their children in a loving, caring manner and making decisions that promote their welfare) will unavoidably be linked and supported by their religious views. When it comes to an individual's right to practice their religion, this seems inextricably linked with how an individual wants to raise their child.

Anticircumcision proponents argue that in as much as it is important for parents to be accorded religious liberty (that is, the freedom to appeal to religious principles to guide their moral choices), concomitantly, it is just as important for the child to be accorded religious liberty (the freedom to choose whether he wants to join his parent's religion, another religion, or no religion at all). It is maintained that people are not born with a particular set of religious beliefs and it is not a child's choice to be brought up under certain religious traditions or customs. A valid point; however it would be untenable in practice not to make decisions for children because they may have chosen differently. Infants and children cannot make decisions for themselves, and parents have a duty to make decisions on behalf of their child concerning their wellbeing, such as religious upbringing, choice of schooling, immunisation, living environment, dietary requirements, insurance and investments for the child, and so on. Parents need to have the freedom to make decisions for their children based on what they view as best, on the balance of benefits and risks.
Although I do not have the space to present the arguments here, it would seem that to be successful anticircumcision proponents would have to argue in cases where the right to religious liberty of the parent and the child are in conflict with each other, the child's right should supercede the parent's right, on the grounds that the child may not end up remaining a member of the religious community he is to be brought up in. ${ }^{7}$ It seems to me that such an argument would revolve around whether the practice the parents seeks to justify through their right to religious liberty in the face of their child's claim would be whether the practice is reasonable or not. Surely, what is most salient is not whether a parent has the freedom to use their religious doctrine as a source of value concerning parental decisions, but whether the decisions which stem from the doctrine are reasonable.

David Meeler has recently argued that an appropriate balance is to be found when a follower's rights and liberties as a citizen are reasonably respected by their religion (for example, in this case, whether an infant's rights and liberties are respected by a religious view which mandates male circumcision). ${ }^{8}$ Although it will not be seen as unreasonable for followers of particular religions to have certain freedoms or behaviours restricted or constrained (compared with other citizens who do not subscribe to the religion) the question remains of how we are to determine when such restrictions become unreasonable. In order for anticircumcision proponents to successfully maintain that the freedom of parents to choose whether they ought to have their son circumcised is not a protected incidence of religious liberty (or even parental autonomy, in general), they would have to show that the religious values to which they appeal to justify their decision is unreasonable. ' Many anticircumcision proponents claim that what makes these religious values unreasonable stems from the fact that they ignore the harm that results from circumcision. In the next section, I briefly examine the argument for the prohibition of parents being able to make a choice concerning circumcision, based on the putative harm of the procedure.

\section{(B) Circumcision as a putative harm} Almost all individuals would agree that there are some instances when it is permissible for male circumcision to be performed. In cases of what is termed "therapeutic circumcision" (that is, cases where reasons for the procedure are to remedy an anatomical or pathological condition), most people would view such an intervention as justifiable.
However, it is when circumcision is performed for what is termed "nontherapeutic" reasons that will concern me in this paper. ${ }^{10}$

I cannot hope to present and evaluate all of the medical evidence concerning the potential benefits and risks associated with circumcision. ${ }^{11}$ It is clear that there are potential advantages and disadvantages associated with the procedure; some people believe the medical evidence shows that the procedure is beneficial, whereas others believe that it shows that the procedure is unnecessary or confers negligible results (if any). The only position I do not believe the evidence supports is that the procedure is unequivocally harmful.

When the issue is termed in reference to whether a policy of "routine infant circumcision" would be justifiable, the question becomes is there enough medical evidence that demonstrates that the benefits of undergoing circumcision are so favourable that all healthy male infants should undergo the procedure (or, at least, that the procedure should be recommended to all patients as a routine procedure). Most medical associations, such as the American Academy of Pediatrics, ${ }^{12}$ the British Medical Association, ${ }^{13}$ the Canadian Pediatrics Society, ${ }^{14}$ and the Royal Australasian College of Physicians, ${ }^{15}$ among others, maintain that although there are potential medical benefits associated with the procedure, on balance these benefits do not overwhelmingly support a policy of universal recommendation.

However, this is a different question of whether infant male circumcision is a justifiable procedure-that is, whether the provision of this procedure can be allowed. Most medical associations maintain that it is in fact justifiableno medical body has advocated a policy that calls for the prohibition of circumcision. Although they recognise that existing medical evidence does not support that the procedure that can be universally recommended, they do not believe the medical evidence shows that the procedure is so detrimental that it should be prohibited or outlawed.

Although medical evidence concerning the procedure is of vast importance, I maintain that to view this issue as one solely concerning medical benefit and risk is to draw too narrow a view. The question of the justifiability of circumcision should not be made exclusively along a therapeutic/non-therapeutic distinction because such a view fails to take seriously all of the potential non-medical benefits (and risks) associated with this procedure. In addition to the empirical evidence that supports judgments made by parents concerning the medical benefits or risks of the 
procedure, there are other judgements which inform parents' decisions that have their basis in other factors (such as social, cultural, religious).

Reasonable conceptions of the "good" will differ in how they attribute value to the body, the prudential value of prophylactic health measures, the moral significance of belonging to a community, among many other considerations. We recognise that people will disagree over the value of the procedure (where the value derived may be from a consideration of potential medical and non-medical benefits), and the question concerning a parent's choice is made with respect to the value or disvalue it would bring to their son. What needs to be recognised is that the worth of circumcision is determined by a value judgment made by parents. The argument that the procedure is morally impermissible-that is, regardless of your reasonable concept of the good, the provision of circumcision should not be allowed-is in the wrong justificatory class. It is advocating a substantive moral position, instead of using public reason to arrive at a fair and justifiable policy. It is maintaining that the procedure has no value or has a level of disvalue to such an extent that we must remove a parent's ability to evaluate its merits or distractions. This, I maintain, is a mistake. It is wrong to believe that one can only value circumcision for medical reasons and that circumcision cannot contribute to some children's wellbeing. Although there is much more that could be discussed concerning the objectivity and subjectivity of welfare (especially how non-medical benefits contribute to wellbeing), I cannot discuss further this aspect of the issue here. The argument that circumcision results in a serious harm seems to me to be a more crucial issue. In what follows, I briefly examine three ways in which it is purported that circumcision is harmful: (1) complications from the procedure, (2) subsequent effects of procedure, and (3) a set back to one's rights.

There are two suppositions to my argument. Firstly, it will be taken for granted in this paper that the permissibility of circumcision will presuppose that practitioners are using optimal pain control measures. The medical evidence clearly demonstrates that pain control measures are effective in substantially reducing or eliminating the pain of the procedure. ${ }^{16}$ As with any other medical procedure, I would contend that practitioners not using optimal pain control to alleviate discomfort or pain are falling below a standard of good clinical care. Secondly, it will also be taken for granted that the practitioners will also be adequately trained and sufficiently experienced with the procedure-this not only includes the proven expertise of the operator, but attention to proper operating conditions and adequate aftercare. It is reasonable for parents who choose to have their son circumcised to expect that these conditions will be in place. ${ }^{17}$

The most obvious source of harm that might be observed from circumcision is from complications of the procedure. The complication rate for the procedure is very low; studies show that the incidence of clinically significant complications is $0.9 \%$ to $1.5 \%{ }^{18}$ Particularly as it is the standard of care to provide optimal operative and postoperative pain relief and good aftercare, it will be difficult to convince people that this procedure is harmful on this basis.

Another prominent argument against circumcision is based on the position that subsequent effects of procedure are harmful. Recently, there have been studies documenting that circumcision results in damage to the penis. ${ }^{19}$ Margaret Somerville observes: “... good ethics depend on good facts, and good law depends on good ethics. The medical facts about infant male circumcision have changed as a result of medical research. We now know that infant male circumcision is harmful in itself and has harmful consequences. Circumcision removes healthy, functioning, erogenous tissue that serves important protective, sensory and sexual purposes."20

I would contend that we do not know in any robust or determinate sense that infant male circumcision is harmful in itself, nor can we say the same with respect to its purported harmful consequences. Part of this difficulty in determining what is a harmful consequence stems from the fact that different people will view what is harmful differently. Whether something is a harm will often depend (although not always) on one's conception of the good, the overall value attached to the action/event, how one conducts a cost benefit analysis (for example an individual may make a trade off in favour of some other benefit), among other considerations. The concept of harm is a difficult and complex issue that I do not have the space to explore here, however, it seems that in order for anticircumcision proponents to be successful in their argument, they would have to show that circumcision causally results in a majority of the population who have been circumcised to loose their ability to protect their penises, be sexually stimulated, and so on.

To my knowledge there is no conclusive epidemiological and/or sociological evidence that supports the claim that circumcision constitutes such substantive harm(s); the evidence available is extremely limited and presents contradictory results. ${ }^{21}$ In one of the papers that is often cited by anticircumcision proponents, the claim that circumcision removes an important component of the sensory mechanism of the penis is based on finding of an extremely small sample size $(n=22)$ of cadavers. ${ }^{22}$ Not only is a pathological study not ideal for conclusions concerning the physical sensation and enjoyment of sex in the living, we have no findings that show that sensation transmission pathways of the penis differ substantially between circumcised and uncircumcised men. As it presently stands, there is no convincing evidence that shows that sexual function of circumcised individuals is worsened or damaged as a result of a properly performed circumcision.

When it comes to an adequate assessment of the potential harms of a medical procedure or cultural practice, it is essential that we have reliable empirical evidence on which to construct the debate. In addition, it is also essential that we realise that medical evidence is not the only data that count in the debate-non-medical benefits and risks must also be recognised as valid and relevant factors available for rational criticism and consideration. Let me be clear: the reporting of potential negative effects to parents when making the decision of whether or not it is in their son's interest to be circumcised is very important. However, when it comes to the question of whether these purported effects constitute a harm sufficient to justify prohibiting the practice of circumcision, I do not see the case being adequately made. ${ }^{23}$

\section{(C) Circumcision and the law}

Another prominent argument advanced by anticircumcision proponents in favour of prohibiting the procedure stems from legal (rather than moral or medical) considerations. It has been argued that everything from criminal statutes to human rights legislation could justify prohibiting infant male circumcision, as the procedure could represent a violation or set back to one's rights. For instance, Margaret Somerville has argued that provisions in the criminal code (of Canada) already cover the type of harm purported to be associated with infant male circumcision as an instance of assault, specifically aggravated assault. Where assault is defined as anything more than de minimis contact with another person without their consent, and aggravated assault as touch that results in breaking the full thickness of the skin, circumcision could fall under the definition of aggravated assault. ${ }^{24}$ According to Somerville, surgery avoids being classed 
as aggravated assault in two cases: (1) the surgery, performed by a competent physician, is therapeutic and conducted with the informed consent of the patient (or surrogate decision maker) and (2) the surgery, performed by a competent physician, is non-therapeutic, conducted with the informed consent of the adult patient, and is not contrary to public policy. Somerville believes that infant male circumcision does not fit into either category of justified surgical intervention because the requirement for informed consent cannot be fulfilled by a child and because non-therapeutic circumcision constitutes more than a de minimis (a trifle) intervention. ${ }^{25}$

Others have argued that infant male circumcision is a harm because it violates a child's human rights. Appealing to documents such as the United Nations' International Covenant on Civil and Political Rights, Universal Declaration of Human Rights, and the Convention on the Rights of the Child, various claims have been made that circumcision violates a child's right or freedom with respect to: expression, thought, religion, torture, self determination, dignity, respect, identity, bodily integrity, discrimination, and non-interference, among other things. Some of these arguments are quite weak and specious; others quite challenging and test our considered judgments concerning what rights we ought to accord to children and what acts violate those rights. Space limitations prevent me from fully evaluating the substance and potential success of using human rights arguments to prohibit circumcision. However, in this interesting and unsettled area of inquiry, I want to briefly advance a few problematic features of taking this route.

Although anticircumcision proponents will often recognise the importance of the religious liberty of parents (as a human right), it is claimed that this right should not extend to cases where this religious practice is harmful or violates one of the child's human rights (that is, practices performed under the auspices of religious liberty are justifiable to extent that actions taken do not violate the basic rights and liberties of citizens). ${ }^{26}$ Both claims are far from being evident. In the case of harm, in order for a prohibition against religious circumcision to constitute a reasonable sanction against a religious doctrine, we would be required to settle the issue concerning the putative harmful effects of circumcision. On the balance of evidence, we have no reason to believe that circumcision is a harm that merits state intervention to prohibit its practice. In the case of parents' rights verses children's rights, it is not clear that these rights are actually in conflict, and if they are, it is not clear whether religious liberty rights must be superceded by other competing rights. This, of course, assumes that the human rights provisions of the United Nations actually apply to the case of circumcision, and that infants actually possess all of the human rights outlined in these charters.

In addition to substantive legal questions about conferring human rights to children, there are also important philosophical and jurisprudential implications concerning the question of assigning human rights to children, especially infants. Although we would no doubt agree that we have weighty moral and legal obligations towards infants, it is still controversial whether it is the case that they have all the same legal rights as human beings with agency. Depending on how one justifies a human rights account, for instance whether one uses a personhood or needs based account, the existence conditions of human rights and what kinds of harms will violate these rights will be different. ${ }^{27}$ Rights make important normative claims on individuals, organisations, and governments. Although the normative authority of these rights makes them tempting regulatory avenues to be pursued by anticircumcision proponents, we must be cautious in our thinking concerning the structure, substance, and reach of human rights claims. ${ }^{28}$

I am inclined to believe that allowing a parent to choose whether or not to have their son circumcised does not violate his human rights but, as I said, this would require further argumentation that I cannot provide here. However, I do think this move towards using legal remedies such as human rights legislation to prohibit circumcision signals a significant motivation of anticircumcision proponents. Medical evidence has not justified prohibiting the provision of circumcision. Moral arguments have not been able to justify removing the decision from parents concerning this procedure. However, the move towards employing the law as a means of prohibiting the procedure appears a convenient way to enforce a particular value judgment in a way that appears to remove the moralism inherent in its source. Arguments which seek to prohibit circumcision are predicated on particular conceptions of the good that inform their notion of value, what could contribute to a child's welfare, what factors inform their cost benefit analysis, and so on. Anticircumcision proponents are taking what they believe to be a nonnegotiable moral truth-that circumcision is unequivocally harmful and must be prohibited, whether citizens recognise this harm or not-that is not open to compromise or abandonment, and attempting to institutionalise this judgment in society.
These arguments fail to take as their starting point the fact that a plurality of reasonable individuals will arrive at different conclusions concerning the value of circumcision. Anticircumcision proponents who are seeking to have the procedure prohibited do not appear interested in advancing a policy that could be seen as fair and justifiable to members of society who hold opposing moral commitments on this issue. In light of a diversity of moral views concerning the worth of circumcision, a number of anticircumcision proponents have abandoned the route of public moral deliberation and are seeking legal remedies to enforce their moral view. To me, this seems to be the wrong way to construct biomedical public policy.

\section{(D) Circumcision and health care policy}

What needs to be realised is that the achievement of fair and sustainable public policy cannot be done at the level of conceptions of the good, but must be secured using politically liberal values shared by reasonable members of society. Allowing parents to make decisions concerning what procedures are in their child's interest are justified not because parental autonomy is a value that everyone should uphold but because it is an instance of, as Ainslie has maintained, "the terms for our living together in a society despite our different moral commitments ... For this is the only way to allow each of us to subscribe to our own moral doctrines and yet still live together". ${ }^{29}$

The discussion concerning whether parents should be free to choose whether their son will be circumcised also has an interesting corollary in healthcare systems where there are parallel public and private structures. Governmental involvement or constraints on certain religious practices, such as circumcision, continue to occur. ${ }^{30}$ Recently in a number of jurisdictions in Canada (and earlier in other countries such as England), the provision of infant circumcisions had to be removed from the schedule of covered procedures available as part of the public healthcare service. A number of private insurance carriers and health plans in the United States have also decided not to reimburse the cost of the procedure. The reason for these decisions was based partly on the lack of medical indications for the procedure; however it also saved governments and insurers a large amount of money by having parents pay for the procedure themselves. There were a number of individuals and groups (religious and non-religious) who expressed dissatisfaction with these policy decisions. It 
would be, in my mind, dubious to argue that such a policy would infringe on an individual or group's religious liberty; however it does point to potential implications concerning access to controversial medical services (especially, for instance, in places where healthcare services are scarce or inadequate). Constraints on the practice of circumcision have been noted in the provision of private healthcare services as well. ${ }^{31}$

It is also worth noting that there have been precedents of medical professionals attempting to reach compromises concerning circumcision, in an attempt to accommodate certain religious/cultural practices. In the West Midlands of England, there are some health districts which have provided religious circumcisions (covered by public health system) in order to ensure that they are carried out by skilled practitioners with full anaesthetic to minimise pain and complications. ${ }^{32}$ In the city of Seattle in the United States, the Harborview Medical Center (knowing that if requests to have their daughters "circumcised" were not fulfilled, mothers would seek out the procedure in a non-medical environment) agreed to offer a compromise for the procedure. ${ }^{33}$ They offered to provide a procedure in which the labia or clitoris would not be touched, but a small incision in the clitoral prepuce would be made to draw some blood. Although this compromise would have satisfied some members of the community, opponents of female genital cutting ${ }^{34}$ prevented its provision. It does not seem unreasonable or unattainable to work towards compromises in society that respect the multitude of different moral commitments in a way that does not violate our considered judgments about what justice demands. Although the harm that clitorectomies and infibulation cause is not permissible, this does not mean we do not have an obligation to find ways of accommodating different cultural practices. As in the case of the compromise offered by the Harborview Clinic, we should endeavour to take measures that aim to respect the value judgments and cultural practices of others in a way that reduces the mortality and morbidity that would result from individuals seeking female genital cutting elsewhere. Such an attitude of tolerance does not seek to provide a moral defence of the particular practice, but can be judgmental towards particular practices in a way that respects the values of other cultures while reducing the potential for harm.

Finally, there is one last pertinent issue that needs to be raised. If the provision of circumcision were actually prohibited from being preformed by medical practitioners and state licensed professionals, what kind of weight should be accorded to the very likely possibility that individuals would continue to seek such a procedure regardless of what the law permits? Given that the practice of male circumcision is such an important aspect of Muslim and Jewish religious observance (and the practice would continue to have important social value for other members of society as well), to what extent would the state and medical establishment have to take seriously the ramifications of individuals obtaining the procedure for their children elsewhere in society? Any policy that would seek to make circumcision prohibited (or using the existing criminal law to affect the same outcome) would quite likely result in the practice being driven underground with predictably dire results. As it has been seen with other medical procedures that have been outlawed by the state-for example, the most vivid case in recent history is abortion-unqualified or lesser qualified practitioners will step in to fill the gap in the market. Such a state of affairs would put boys in much greater risk of harm. I do not suggest that this reason would justify the continued provision of the procedure itself; however, the potential harm resulting from botched underground medical procedures would have to be taken into account when evaluating the overall benefits and costs associated with a policy prohibiting circumcision.

III

Medical professionals, especially those engaged in setting policy such as bioethicists, must take as their starting point the fact that reasonable people will disagree about what is valuable and what is harmful. They have an obligation to construct institutional norms and policies that do not presuppose or enforce a particular moral or political doctrine. There is a need to differentiate between rituals and practices that are in fact grievously harmful and those which relate to the enhancement of a child's religious and cultural identity. I do not believe it has been shown that a compelling interest would be served by using the law to prohibit a parent from justifying their decision whether or not to circumcise their son based on appeals to their evaluative judgments. Circumcision is a significant feature of the Jewish and Muslim faiths and any policy or legislative action seeking to prohibit its provision will be opposed by both religious communities (and those who believe that this practice should be justifiably protected as an instance of religious liberty).
This freedom, however, does not come without responsibilities. Both medical practitioners and parents have important responsibilities concerning the decision to circumcise. Parents need to take measures to educate themselves about all of the potential benefits and risks of the procedure. Medical practitioners must be ready to provide adequate, accurate, and unbiased information to parents about all of the potential benefits and risks of the procedure. $^{35}$

In summary, the case against allowing parents to choose whether circumcision is or is not in their son's interest has not been conclusively made. In our pluralistic society, there will be marked diversity between reasonable conceptions of the good concerning what interventions are valuable or promote a child's welfare. Even in contexts when such interventions are medical in nature, the potential benefits or risks associated with the child's welfare concerns will often involve medical, social, and cultural factors. As it presently stands, there is an absence of sufficient evidence or persuasive argumentation to warrant changing the current policythat parents should have the freedom to make an informed and well deliberated choice concerning whether the procedure is in their son's interest.

J Med Ethics 2004;30:241-247.

doi: 10.1136/jme.2003.003921

Correspondence to: A M Viens, Department of Philosophy, St Anne's College, Oxford University, Oxford, UK; adrian.viens@ philosophy.ox.ac.uk

This commentary was peer reviewed by an external referee.

\section{REFERENCES}

1 Hutson JM. Circumcision: a surgeon's perspective. J Med Ethics 2004;30:238-40.

2 I believe that the term "routine infant circumcision" is a misnomer. It denotes a position that nobody really holds, namely that as a matter of routine, all healthy boys should be circumcised. Opposition to a policy of "routine infant circumcision" does not have to indicate opposition to a parent's right to choose for their son to undergo the procedure, nor the provision of the procedure in general.

3 Somerville MA. The ethical canary: science, society and the human spirit. Toronto: Penguin, 2000:202-19.

4 This political conception is most vividly argued for by Rawls J, Political liberalism. New York: Columbia University Press, 1996.

5 Ainslie DC. Bioethics and the problem of pluralism. Soc Philos Policy 2002;19:1-28 (see pl4).

6 By religious liberty in the context of bioethics, I mean the legitimacy and extent to which individuals and/or groups should be able to use religious principles and beliefs to make decisions concerning the desirability or exemption of medical procedures and treatments.

7 However, there would have to be a difficult cost/ benefit analysis made concerning the cost of being circumcised and not becoming an adherent of your parent's religion versus not being circumcised and being brought up in the faith community where it is prescribed. It would require 
a complex argument on both sides; however, I am inclined to believe that it would be difficult to successfully argue that, on balance, it would be more detrimental to have the parent's right to religious freedom trump their child's right rather than vice versa in this particular case.

8 Meeler D. Reasonable sanctions for reasonable doctrines. J Soc Phil 2000;31:153-9.

9 This is a different question from whether a religious doctrine is unreasonable. The question of whether the religious mandate for circumcision is unreasonable and justifiably prohibited-for instance it violates a person's rights and/or liberties as citizens - is examined in II (C).

10 Moreover, although I am primarily concerned with "non-therapeutic" infant male circumcisions required as religious rites of passage, I am inclined to believe that what I have to say can also apply to parents who decide to have their son circumcised on value judgments of a non-religious nature.

11 For detailed examinations of some of this literature, see Niku SD, et al. Neonatal circumcision. Urol Clin North Am 1995;22:5765; Benatar M, Benatar D. Between prophylaxis and child abuse: the ethics of neonatal male circumcision. Am J Bioeth 2003:3:35-48. That is not to say that I will not be relying on medical evidence in this paper, only that I will not be using it to advance a substantive position concerning the overall benefits or risks of circumcision.

12 American Academy of Pediatrics (Task Force on Circumcision). Circumcision policy statement. Pediatrics 1999; 103:686-93

13 British Medical Association. The law and ethics of male circumcision: guidance for doctors (March 2003)

14 Canadian Paediatric Society (Fetus and Newborn Committee). Neonatal circumcision revisited. CMAJ 1996;154:769-80. This statement was reaffirmed in March 2002. In this report, the committee only considered medical evidence: "religious and personal values were not included in the assessment".

15 Royal Australasian College of Physicians (Paediatrics and Child Health Division). Position statement on circumcision, Sydney: Royal Australasian College of Physicians, 2002. This statement was developed as a unified position of six medical societies in Australia and New Zealand: the Royal Australian College of Physicians, the Australian Association of Paediatric Surgeons, the New Zealand Society of Paediatric Surgeons, the Urological Society of Australasia, the Royal Australasian College of Surgeons, and the Paediatric Society of New Zealand.

16 In addition to the use of a dorsal penile nerve block or subcutaneous ring block, the use of other interventions to minimise operative and postoperative pain, such as sucrose pacifier, buffered lidocaine, small needles, acetaminophen, swaddling, environmental modification, topical anaesthetic (for example, EMLA) are all useful measures should be employed. See Geyer J, Ellsbury D, Kleiber C, et al. An evidence-based multidisciplinary protocol for neonatal circumcision pain management. J Obstet Gynecol Neonatal Nurs 2002;31:40310; Litman RS. Anesthesia and analgesia for newborn circumcision. Obstet Gynecol Surv. 2001;56:114-17; Kraft NL. A pictorial and video guide to circumcision without pain. Adv Neonatal Care 2003;3:50-62; Taddio A, Pollock N Gilbert-MacLeod C, et al. Combined analgesia and local anesthesia to minimize pain during circumcision. Arch Pediatr Adolesc Med 2000;154:620-3.

17 I am primarily concerned with circumcisions that take place in a medical environment (for example, a clinic or hospital). However, I still believe that there is an obligation to obtain a skilled practitioner and proper pain control measures for circumcisions performed in a non-medical setting.

18 Gee WF, Ansell JS. Neonatal circumcision: a tenyear overview: with comparison of the Gomco clamp and Plastibell device. Pediatrics 1976;58:824-7, 824; Wiswell TE, Geschke DW. Risks from circumcision during the first month of life compared with those for uncircumcised boys.
Pediatrics 1989;83:1011-15; Fredman, RM. Neonatal circumcision: a general practitioner survey. Med J Aust 1969;1:117-20. Such figures will vary depending on what is classified as a complication.

19 Cold CJ, Taylor JR. The prepuce. BJU Int 1999;83(Suppl 1):34-44.

20 Somerville 2000.

21 Fink KS, Carson CC, DeVellis RF. Adult circumcision outcomes study: effect on erectile function, penile sensitivity, sexual activity and satisfaction. J Urol 2002;167:2113-16; Collins S, Upshaw J, Rutchik $\mathrm{S}$, et al. Effects of circumcision on male sexual function: debunking a myth? J Urol 2002;167:2111-12; Laumann EO, Masi, CM, Zuckerman, EW. Circumcision in the United States. Prevalence, prophylactic effects, and sexual practice. JAMA 1997;277:1052-7.

22 Taylor JR, Lockwood AP, Taylor AJ. The prepuce: specialized mucosa of the penis and its loss to circumcision. Br J Urol 1996:77:291-5.

23 There is indeed anecdotal evidence and case studies of a very small fraction of men circumcised as infants (and an even smaller number of men circumcised as adults) who report regretting having undergone the procedure. To my knowledge, there is no strong medical or epidemiological evidence concerning, for instance, the comparative differences in sensation or body image between circumcised or uncircumcised men that would support a findin that men who were circumcised were substantially harmed. However, the use of anecdotal evidence would not seem to bolster the anticircumcision position, as a vast majority of circumcised men appear satisfied with their status or do not feel harmed or damaged for undergoing the procedure. It would be beneficial to have more evidence concerning the comparative sexual functioning between circumcised and uncircumcised men, although the inheren subjectivity of such reporting would make it difficult to assess the effects of the comparative states. It would nonetheless be helpful to have more evidence in this area to inform the current debate.

24 Somerville 2000. Somerville's position on religious circumcision is more permissive compared to non-religious circumcision. She believes "only those who believe they have a fundamental, absolute religious obligation to carry out infant male circumcision should be exempt from a prohibition on it ${ }^{\prime \prime}$. However, if circumcision is the harm she makes it out to be, this exemption seems arbitrary and tenuous. As much as it seems that circumcision should be protected as an instance of religious liberty, why should we privilege religious value judgments over other non-religious value judgments? And what would stop others from going further and saying that no value judgments (religious or otherwise) could justify a parent's decision to circumcise their son?

25 The question of how far a parent's ability to consent (on behalf of their children) extends is an important one. For instance, it has been maintained that a parent can only have the legal power to consent to a procedure that removes tissue when it is necessary for the diagnosis or treatment of disease (and only when that procedure is foreseen to present with negligible risk and minimal burden). See Nuffield Council on Bioethics. Human tissue: ethical and legal issues. London: Nuffield Council on Bioethics, 1995. However, this seems to be too limited. For instance, it has been seen as permissible for older siblings (who are minors) to donate bone marrow to a younger sibling - a procedure which confers no medical benefit for the donor and puts them under considerable risk of harm of death.

26 For instance, the American Academy of Pediatrics' Committee on Bioethics have maintained that "the constitutional guarantees of freedom of religion do not sanction harming another person in the practice of one's religion". Compare with: Committee on Bioethics. American Academy of Pediatrics. Religious objections to medical care. Pediatrics 1997;99:279-81.

27 For an excellent examination of these issues, see Griffin J. Do children have rights? In: David Archard, Colin Mcleod, eds. The moral and political status of children: new essays. Oxford: Oxford University Press, 2002;19-30; Sumner LW. The moral foundations of rights. Oxford: Oxford University Press, 1987:10-11 and 202-5.

28 Sumner puts the point nicely: "like the arms race the escalation of rights rhetoric is out of control. In liberal democracies of the West ... public issues are now routinely phrased in language of rights" (1987:1).

29 Ainslie 2002:17

30 For instance, in October 2001, a new law in Sweden stipulates that a licensed doctor can only perform circumcisions or a person certified by the National Board of Health (in the case of circumcisions performed by mohels, there were additional requirements that they be

accompanied by a physician or nurse for anaesthesia). The Jewish community objected to the law claiming it interferes with their religious traditions. Department of State, United States Government. "Sweden" in The International Religious Freedom Report 2002. (http:// www.state.gov/g/drl/rls/irf/2002/13983.htm). I am inclined to believe that most members of the religious community would agree that although it is an interference with religious tradition, it is a reasonable constraint on the practice.

31 At the Rainbow Flag Health Service Sperm Bank in Alameda, California, the clinic has a policy not to offer its services to individuals who would want to have their son circumcised (http://

www.gayspermbank.com/philosophy.htm). Although there is no positive obligation on medical practitioners to perform circumcisions, it is worth considering the extent to which limits to such a procedure actually, if at all, impinges on religious liberty. This, however, is a separate, yet related, consideration concerning the ability of parents to access this procedure in a hospital or clinical setting, and not the ability of parents to practice the rite of circumcision (for example, as a religious ceremony in the home or place of worship).

32 Rickwood AMK, Kenny SE, Donnell SC. Towards evidence based circumcision in English boys: survey of trends in practice. $B M$ 2000;321:792-3.

33 Celia W. Dugger. Tug of taboos: African genita rite vs. US law. New York Times 12 December 1996), p 9; Coleman DL. The Seattle compromise: multicultural sensitivity and americanization. Duke Law Journal 1998;47:717-83.

34 I use the term female genital cutting, instead of "female circumcision" in order to make clear the marked difference between this procedure and male circumcision. The removal of the male foreskin is in no way similar or equivalent (morphologically or symbolically) to the removal of the clitoris and/or labia.

35 Studies have shown that parents are often unhappy with the information they receive from physicians about circumcision. See Adler R, Ottaway S, Gould S. Circumcision: we have heard from the experts; now let's hear from the parents. Pediatrics 2001;107:e20. This study demonstrated that satisfaction with a parent's decision concerning circumcision was highly correlated with the discussion and information provided by the medical profession. However there are other studies which show that many parents make their decision whether or not to circumcise their son prior to discussions with physicians, and physician discussions appear to have little impact on a parent's decision. See Tiemstra JD. Factors affecting the circumcision decision. J Am Board Fam Pract 1999; 12:16-20; Brown MS, Brown CA. Circumcision decision: prominence of social concerns. Pediatrics 1987;80:215-19. Bean GO, Egelhoff C. Neonatal circumcision when is the decision made? J Fam Pract 1984; 18:883-7. Nevertheless, although physician discussion may ultimately have little affect in changing a parent's mind (for example, if a parent does not believe a circumcision is in her son's interest, then having a physician present its potential benefits will not tend to change their decision) we have good reason to require that parents are presented with all potential benefits and risks for the purposes of ensuring fully informed consent. 